\title{
La aplicación de la vacuna contra el virus del papiloma humano no aumentaría la incidencia de enfermedades de trasmisión sexual en mujeres adolescentes
}

Application of human papillomavirus vaccine would not increase incidence of sexually transmitted infections among adolescent females.

JAMA Intern Med. 2015;175(4):617-623

\section{Objetivo}

Determinar si la vacunación contra el virus del papiloma humano (VPH) se asocia a un aumento de la tasa de enfermedades de trasmisión sexual (ETS) en adolescentes.

\section{Diseño, lugar y población}

Se realizó un estudio de cohorte retrospectiva.

A partir de múltiples bases de datos de compañías aseguradoras de salud, se seleccionó un grupo de mujeres de entre 12 y 18 años de edad que recibieron una dosis de la vacuna Gardasil entre el año 2005 y 2010 en Estados Unidos. Aquellas mujeres que habían recibido la vacuna bivalente (Cervarix) fueron excluidas por haber sido aprobada al final del estudio.

\section{Medición de resultados principales}

Por cada mujer vacunada se eligieron una o más mujeres no vacunadas que coincidieran en edad, código postal y sistema de salud. Se utilizó un análisis de tipo "difference-in-difference" para comparar las tasas de ETS previa y posterior a la vacunación. De esta manera se estimaron cambios en la tasa de ETS antes y después de la vacunación y se compararon estos cambios con aquellos en el grupo de mujeres no vacunadas.

\section{Resultados principales}

La tasa de ETS previa a la vacunación fue mayor en el grupo de mujeres que recibieron la vacuna en comparación con aquellas mujeres no vacunadas. La tasa de ETS aumentó en ambos grupos en el año posterior a la vacunación. Ver tabla 1. El odds ratio (OR) obtenido a partir del análisis "difference-indifference" fue de 1,05 (IC 95\% 0,8 a 1,38).

Tabla 1: Tasa de enfermedades de transmisión sexual previa y posterior a la vacunación para VPH

\begin{tabular}{c|c|c|c|c}
\begin{tabular}{c|c|c|} 
Estado de \\
vacunación
\end{tabular} & $\begin{array}{c}\text { Tasa de eventos de ETS } \\
\text { prevacunación } \\
\text { N (Tasa/1000) }\end{array}$ & $\begin{array}{c}\text { Prevacunación para VPH } \\
\text { OR (IC 95\%) }\end{array}$ & $\begin{array}{c}\text { Tasa de eventos de ETS } \\
\text { postvacuunación } \\
\mathbf{N}(\text { Tasa/1000) }\end{array}$ & $\begin{array}{c}\text { Postvacunación para VPH } \\
\text { OR (IC 95\%) }\end{array}$ \\
\cline { 1 - 2 } $\begin{array}{l}\text { Pacientes con } \\
\text { vacunación VPH }\end{array}$ & $94(4,3)$ & \multirow{2}{*}{$1,37(1,09 \mathrm{a} 1,71)$} & $147(6,8)$ & \multirow{2}{*}{$1,50(1,25 \mathrm{a} 1,79)$} \\
\hline $\begin{array}{l}\text { Pacientes sin } \\
\text { vacunación VPH }\end{array}$ & $522(2,8)$ & $781(4,2)$ & \\
\hline
\end{tabular}

ETS: enfermedades de transmisión sexual; VPH: virus del papiloma humano; OR: odds ratio

\section{Conclusiones}

No se encontró evidencia de que la vacunación contra el VPH se asocie a un aumento en la tasa de ETS en mujeres adolescentes.
Fuente de financiamiento/conflicto de interés: National Institutes of Health (NIH)/Ninguno

\section{Comentario}

En relación a la metodología de la investigación, los autores del presente estudio se enfrentaron a un problema al seleccionar la población del mismo. Al analizar las características de la población elegida, observaron que la tasa de ETS previa a la vacunación en las mujeres vacunadas era mayor que en aquellas no vacunadas. Esto implicó la necesidad de realizar un análisis estadístico que disminuyera el sesgo de selección. Por otro lado, los datos que se utilizaron (vacunación, consultas por ETS, anticoncepción, etc.) fueron obtenidos de sistemas de salud privados sin tener en cuenta centros de salud gratuitos. Un detalle a considerar es que en los Estados Unidos no existe obligatoriedad para la aplicación de las vacunas sugeridas en el calendario de vacunación. Según datos del año 2013, sólo el $57 \%$ de las adolescentes estadounidenses entre 13 y 17 años de edad recibió la vacuna contra el $\mathrm{VPH}^{1}$. En un estudio publicado en la revista Pediatrics se analizaron las barreras que los médicos pediatras y de familia percibían para la indicación de la vacuna. Si bien la mayoría recomienda fuertemente la vacunación, esta sugerencia se debilita en las niñas de 11 años (edad mínima sugerida para iniciar la vacunación). Dos factores surgieron como barreras para la vacunación a temprana edad: la necesidad de abordar en primera instancia temas de sexualidad y la oposición de los padres ${ }^{2}$. En Argentina, la vacuna contra el VPH fue incluida en el año 2011 en el calendario nacional de vacunación para niñas a partir de los 11 años de edad y con un esquema de tres dosis. Posteriormente en mayo de 2015 se simplificó el esquema a dos dosis.

\section{Conclusiones del comentador}

Un preconcepto, afortunadamente poco extendido, que es considerar que la vacunación contra el VPH podría motivar las relaciones sexuales no protegidas, fue rebatido por los resultados del presente estudio. Desde nuestro rol como médicos de familia, deberíamos contribuir a la erradicación de tales prejuicios brindándole a nuestras adolescentes y sus padres la información necesaria para promocionar una salud sexual segura, libre de violencia y enfermedades.

\section{María Emilia Espósito [ Servicio de Medicina Familiar y Comunitaria del Hospital Italiano de Buenos Aires. mariaemilia.esposito@hospitalitaliano.org.ar ]}

Espósito ME. La aplicación de la vacuna contra el virus del papiloma humano no aumentaría la incidencia de enfermedades de trasmisión sexual en mujeres adolescentes. Evid Act Pract Ambul 2016;19(4):120. Comentado de: Jena AB, Goldman DP, Seabury SA. Incidence of Sexually Transmitted Infections After Human Papillomavirus Vaccination Among Adolescent Females. JAMA Intern Med. 2015 Apr;175(4):617-23.PMID: 25664968.

\section{Referencias}

1. Stokley S, et al; Immunization Services Division, National Center for Immunization and Respiratory Diseases, Centers for Disease Control and Prevention (CDC). Human papillomavirus vaccination coverage among adolescents, 2007-2013, and postlicensure vaccine safety monitoring, 2006-2014—United States. MMWRMorb Mortal Wkly Rep. 2014;63(29):620-624

2. Daley M, et al; Human Papillomavirus Vaccination Practices: A Survey of US Physicians 18 Months After Licensure, Pediatrics, $2010 ; 120$ (3):425-433. 